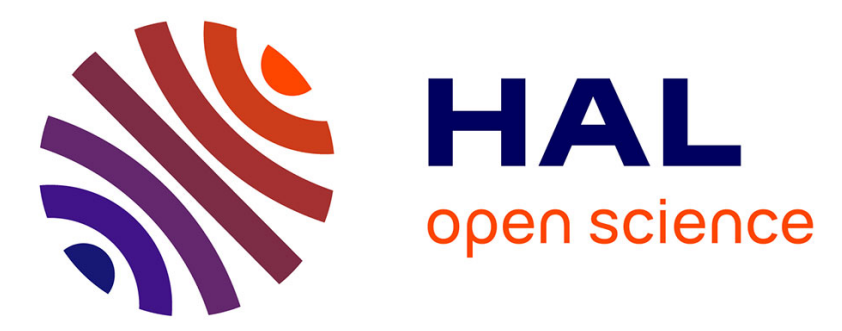

\title{
Sex and the money - How gender stereotypes modulate economic decision-making: An ERP study
}

Eve F. Fabre, Mickael Causse, Francesca Pesciarelli, Cristina Cacciari

\section{To cite this version:}

Eve F. Fabre, Mickael Causse, Francesca Pesciarelli, Cristina Cacciari. Sex and the money - How gender stereotypes modulate economic decision-making: An ERP study. Neuropsychologia, 2015, vol. 75, pp. 221-232. 10.1016/j.neuropsychologia.2015.06.013 . hal-01503693

\section{HAL Id: hal-01503693 \\ https://hal.science/hal-01503693}

Submitted on 7 Apr 2017

HAL is a multi-disciplinary open access archive for the deposit and dissemination of scientific research documents, whether they are published or not. The documents may come from teaching and research institutions in France or abroad, or from public or private research centers.
L'archive ouverte pluridisciplinaire HAL, est destinée au dépôt et à la diffusion de documents scientifiques de niveau recherche, publiés ou non, émanant des établissements d'enseignement et de recherche français ou étrangers, des laboratoires publics ou privés. 


\section{Open Archive TOULOUSE Archive Ouverte (OATAO)}

OATAO is an open access repository that collects the work of Toulouse researchers and makes it freely available over the web where possible.

This is an author-deposited version published in: http://oatao.univ-toulouse.fr/ Eprints ID: 16104

To link to this article: DOI: 10.1016/j.neuropsychologia.2015.06.013 URL: http://dx.doi.org/10.1016/j.neuropsychologia.2015.06.013

To cite this version: Fabre, Eve F. and Causse, Mickael and Pesciarelli, Francesca and Cacciari, Cristina Sex and the money - How gender stereotypes modulate economic decision-making: An ERP study. (2015) Neuropsychologia, 75. pp. 221232. ISSN 0028-3932

Any correspondence concerning this service should be sent to the repository administrator: staff-oatao@listes-diff.inp-toulouse.fr 


\title{
Sex and the money - How gender stereotypes modulate economic decision-making: An ERP study ${ }^{\text {is }}$
}

\author{
Eve F. Fabre ${ }^{\mathrm{a}, \mathrm{b}, *}$, Mickael Causse $^{\mathrm{b}}$, Francesca Pesciarelli ${ }^{\mathrm{a}}$, Cristina Cacciari ${ }^{\text {a }}$ \\ a Department of Biomedical, Metabolic and Neurological Sciences, University of Modena and Reggio Emilia, 41100 Modena, Italy \\ ${ }^{\mathrm{b}}$ Institut Supérieur de l'Aéronautique et de l'Espace, 31400 Toulouse, France
}

Keywords:

Decision-making

Ultimatum Game

Gender stereotypes

Responder

FRN

P3b

\begin{abstract}
A B S T R A C T
In the present event-related potential study, we investigated whether and how participants playing the ultimatum game as responders modulate their decisions according to the proposers' stereotypical identity. The proposers' identity was manipulated using occupational role nouns stereotypically marked with gender (e.g., Teacher; Engineer), paired with either feminine or masculine proper names (e.g., Anna; David). Greater FRN amplitudes reflected the early processing of the conflict between the strategic rule (i.e., earning as much money as possible) and ready-to-go responses (i.e., refusing unequal offers and discriminating proposers according to their stereotype). Responders were found to rely on a dual-process system (i.e., automatic and heuristic-based system 1 vs. cognitively costly and deliberative system 2), the P300 amplitude reflecting the switch from a decision making system to another. Greater P300 amplitudes were found in response to both fair and unfair offers and male-stereotyped proposers' offers reflecting an automatic decision making based on heuristics, while lower P300 amplitudes were found in response to $3 €$ offers and the female-stereotyped proposers' offers reflecting a more deliberative reasoning. Overall, the results indicate that participants were more motivated to engage in a costly deliberative reasoning associated with an increase in acceptation rate when playing with female-stereotyped proposers, who may have induced more positive and emphatic feelings in the participants than did malestereotyped proposers. Then, we assume that people with an occupation stereotypically marked with female gender and engaged in an economic negotiation may benefit from their occupation at least in the case their counterparts lose their money if the negotiation fails.
\end{abstract}

\section{Introduction}

The interest on how social and emotional information affects economic decision-making has steadily grown over the past decades (for overviews, see Frith and Singer, 2008; Rilling and Sanfey, 2011). A key insight on the influence of social aspects on economic decision-making has come from studies using a well-known paradigm, the ultimatum game (Güth et al., 1982). In the classic version of this two-player game, a proposer offers to split a fixed amount of money (e.g., 10€) to a responder. Both get their shares only if the responder accepts the offer. When game partners behave as the self-interested, income maximizer homo economicus

The present research has been funded by the European Community's Seventh Framework Program (FP7/2007-2013) under Grant agreement no. 237907. We would like to acknowledge Marcello Gallucci, Gautier Durantin and Louise Giraudet for their help and support.

* Corresponding author at: Institut Supérieur de l'Aéronautique et de l'Espace, 31400 Toulouse, France.

E-mail address: eve.fabre@isae.fr (E.F. Fabre).
(Camerer, 2003; Gaertig et al., 2012), predictions are straightforward: proposers should offer the smallest amount of money and responders should accept any kind of offer. However, a range of studies demonstrates that the great majority of people deviate from utility-based expected behaviors (Camerer, 2003). Indeed, proposers mainly offer shares close to a 50-50 division (Thaler, 1988; Roth, 1995; Güth, 1995; Camerer and Thaler, 1995) and responders reject low shares (i.e., $20 \%$ of the total or less) in more than 50\% of the cases (Güth et al., 1982; Camerer, 1999, 2003; Sanfey, 2009).

Models of social preference diversely accounted for responders' rejection behavior (for a review, see Fehr and Schmidt, 2005). On one hand, theories of inequality aversion (Fehr and Schmidt, 1999) posit that people are simply and naturally averse to unequal distributions. On another hand, theories of negative reciprocity ( $\mathrm{Ra}-$ bin, 1993; Falk and Fischbacher, 2006) focus on proposers' intentions, describing the rejection as a way to punish selfish proposers at a personal cost for behaving in a self-interested manner (i.e., altruistic punishment; Fehr and Gächter, 2002). In parallel, several 
studies also support the theory according to which the negative emotions (e.g., anger, disappointment, frustration) triggered by the reception of a share deviating from equity, may account for the rejection of unfair offers (Pillutla and Murnighan, 1996; Sanfey et al., 2003; Van't Wout et al., 2006; Koenigs and Tranel, 2007). Indeed, as altruistic punishment was found to be rewarding for the "punisher" (De Quervain et al., 2004), responders may derive satisfaction from rejecting unequal shares, which may help to limit the impact of negative emotions triggered by the reception of unequal shares. However, other studies using a modified version of the ultimatum game paradigm (i.e., third party ultimatum game; Güth and Van Damme 1998), tend to demonstrate that, even though emotional concerns may play a critical role in the decision making process, they should not be the only explanation for the observed rejection behavior (Civai et al., 2010; Corradi-Dell'Acqua et al., 2013; Civai (2013)) argued that inequality rejection may be considered as a cognitive heuristic, i.e. an easy to implement short cut "rules of thumb". Indeed, an important quantity of studies support the existence of a dual-process system in decision making (for a review, see Sanfey and Chang, 2008), with an automatic, fast, effortless, unconscious, associative and slow learning system 1 used for automatic and heuristic-based judgments and a controlled, slow, effortful, conscious and fast learning system 2 underpinning a more deliberative reasoning. Civai maintains that responders may adopt ready-to-go default responses based on internal heuristics consisting in accepting fair offers and rejecting unfair ones. In contrast, in the case of mid-value offers (i.e., $3 €$ out of $10 €$ ), system 2 may override system 1, devoting more cognitive resources to a more complex and time-consuming processing (i.e., deliberative reasoning) associated with less predictable decisions.

\subsection{The impact of social information on fairness consideration}

The results of several recent studies converge to show that the proposers' personal descriptions involved in the ultimatum game bias the way responders consider fairness. Features such as humaneness (e.g., Van't Wout et al., 2006), physical attractiveness (e.g., Solnick and Schweitzer, 1999; Marchetti et al., 2011), intentionality (e.g., Sutter, 2007), possession of positive versus negative traits (e.g., Ruz et al., 2011; Marchetti et al., 2011; Gaertig et al., 2012; Qu et al., 2013), social ties (e.g., Campanhã et al., 2011), social comparison (Wu et al., 2011) or initial ownership (Wu et al., 2012) contribute importantly to modulate the responders' rejection behavior. Various studies investigated the impact of proposers' gender on the responder's behavior. Overall, these studies found that the responders more frequently accepted the shares offered by female proposers than by male proposers (Eckel and Grossman, 2001; Solnick, 2001). The authors interpreted these results to reflect chivalry of male responders toward female proposers and cooperation between female proposers and female responders. Finally, one recent study investigated the impact of racial stereotypes on fairness consideration (Kubota et al., 2013). Responders were found to accept more frequently the offers and on average lower amounts from White proposers than from Black proposers, demonstrating that racial stereotypes affect the fairness consideration of an offer. However, the impact of gender stereotypes on fairness perception has never been investigated.

\subsection{Electrophysiological correlates of the responder playing the ul- timatum game}

Due to their high temporal resolution, the event related potentials (ERPs) provide a valuable source of evidence on real-time neurocognitive processes (Luck and Kappenman, 2012). For this reason, in recent years, the ERPs have been widely used to assess cognitive and affective processes in both economic decision- making (e.g., Nieuwenhuis et al., 2005) and social psychology (for an overview, see Bartholow and Amodio, 2009). While several ERP components have been observed in economic decision-making studies, here, we focus on two of them, specific to the ultimatum game paradigm: The Feedback Related Negativity (FRN) and the P300. The FRN is a negative component observed at frontal-central sites that reaches its maximum in the $200-300 \mathrm{~ms}$ time windows after the stimulus onset (for an overview, see Walsh and Anderson, 2012). Convergent findings from sources modeling and single unit recording suggest that the FRN is generated by the anterior cingulate cortex (ACC; Gehring and Willoughby, 2002; Holroyd and Coles, 2002; Miltner et al., 2003; Nieuwenhuis et al., 2003; Amiez et al., 2005; Brown and Braver, 2005; Folstein and Van Petten, 2008). The P300 is the most investigated and discussed ERP component, emerging in the 300-600 ms time window after stimulus onset (for a recent overview, see Luck and Kappenman, 2012). The P300 is thought to reflect high order cognitive operations such as, for instance, context updating in working memory, attention selection, subjective probability assessment, mental resource allocation and categorization processes (Donchin and Coles, 1988; Verleger, 1988; Kok, 2001).

Several studies recently investigated fairness consideration and the associated neural correlates using the ultimatum game paradigm (Polezzi et al., 2008; Campanhã et al., 2011; Wu et al., 2011, 2012; Alexopoulos et al., 2012, 2013; Qu et al., 2013). Overall, a greater negativity of the FRN component was found in response to unfair offers than to fair offers (Polezzi et al., 2008; Wu et al., 2011, 2012; Alexopoulos et al., 2012, 2013; Qu et al., 2013); and more interestingly, also in response to extra-fair offers (i.e., shares superior to half the amount of money to split) compared to fair offers (Wu et al., 2012). The FRN has been shown to be sensitive to social expectancy and social norms violation in social paradigms (Boksem and DeCremer, 2010; Wu et al., 2012). To this extent, Wu et al. (2012) proposed that non-equal offers (i.e., inferior or superior to the half-share) in the ultimatum game may constitute a particular case of social norm violation (i.e., equality expectancy violation) associated with a greater FRN effect compared to when the fairness norm is applied (i.e., a major negativity for non-equal shares than for equal shares). Two studies also found a greater P300 amplitude in response to fair offers compared to unfair offers (Wu et al., 2012; Qu et al., 2013). The authors interpreted this effect to reflect the greater motivational significance to fair shares than to unfair shares.

Some of these studies using the ultimatum game paradigm also found the FRN and the P300 amplitudes to be modulated by the players' social features. A recent study showed that when the proposer was a friend rather than an unknown person, the FRN typically associated with unfair offers was reversed to positive polarity (Campanhã et al., 2011). In another study, unfair shares were found to elicit a greater negativity of the FRN when offered by proposers who previously socially excluded the responder (i.e., Cyberball game manipulation) than unfair shares offered by proposers that included the responders (Qu et al., 2013).

A recent study showed that the nature of the shares offered to the third person in the third ultimatum game paradigm did not affect the amplitude of the FRN of the participants playing as responders (Alexopoulos et al., 2012, 2013). Moreover, another study also demonstrated that making the responders compare the share they were proposed to shares received by others responders playing in different players' dyad did not lead to a modulation of the amplitude of the FRN (Wu et al., 2011). However, the P300/LPP component was more positive for moderately unequal shares compared to highly unequal shares when the other responders were offered less compared to the participants. Finally, the initial ownership of the asset (i.e., property of either the proposer or the responder) did not affect the FRN amplitude observed in response 
to the shares proposed to the responders (Wu et al., 2012). However, the P300 amplitude was greater when the initial ownership belonged to the proposer than to the participants playing as responders.

To sum up, basic features characterizing the proposers, like their social behavior or social bonds, modulate the FRN amplitude and may reflect the early impact of socio-emotional evaluation on the fairness consideration of an offer (Campanhã et al., 2011; Qu et al., 2013). However, much complex notions such as social preference (i.e., concern for the well-being of others), social comparison or initial ownership may be reflected in the P300/LPP component that is associated with later top-down controlled processes.

\subsection{Why investigating the impact of gender stereotypes on fairness perception?}

Gender stereotypes are a form of social knowledge linked to actions, attitudes, rules and other forms of knowledge (e.g., behavioral representations) attributed to specific social groups according to their biological gender (Greenwald et al., 2000; Wheeler and Petty, 2001; Quadflieg and Macrae, 2011). While the impact of gender stereotypes has been extensively investigated in both social and psycholinguistic studies (e.g., Cacciari and Padovani, 2007; Pyykkönen et al., 2010; Siyanova-Chanturia et al., 2012), the way they impact economic decision-making and more specifically fairness consideration during an economic interaction has been neglected. According to Wood and Eagly (2002), “division of labor emerges from a set of socioeconomic and ecological factors that interact with the physical sex differences inherent in female reproductive activity and male size and strength". Consequently, many female occupational roles are associated with communal traits (e.g., kindness, nurturance, welfare of others) required by women's domestic and childcare roles, while male occupations produce expectations of agentic traits (e.g., leadership qualities, competition, confidence) needed to achieve the primary family provider role (Eagly et al., 2000). To this extent, many occupations are stereotypically marked with gender. Nowadays, an increasing amount of women have access to occupations with a highly marked male stereotype (e.g., lawyer, banker, doctor) while men are also more present in occupations with a highly marked female stereotype (e.g., nurse, "mid-wife", teacher; Eagly, 1987; Rudman, 1998; Eagly and Karau, 2002; Phelan et al., 2008; Rudman and Phelan, 2008). As men and women are constantly led to interact economically, it is important to understand the consequences of this slow society metamorphosis on fairness perception and how it could affect economic interactions.

\subsection{The present study}

Despite the steadily growing interest in understanding the neural basis of economic decision-making, so far, no studies tested the impact of gender stereotypical beliefs on the ultimatum game. Hence, the general aim of this study is to investigate the effects of this specific aspect of the proposers' social identity on the responders' behavior and the associated electrophysiological activity. In the present study, participants play a one shot ultimatum game as responders. They have to accept or reject three different types of shares out of $10 €$ : fair (i.e., $5 €$ ), mid-value (i.e., $3 €$ ) and unfair (i.e., $1 €$ ). Each offer is preceded by a description of the proposer who makes this offer, consisting of an occupational role noun stereotypically marked with gender (henceforth male and female occupational stereotypes, e.g., "ingegnere", engineer; "insegnante", teacher) followed by a masculine or a feminine proper name (e.g., Giorgio ${ }_{\mathrm{MASC}}$, Luisa $_{\mathrm{FEM}}$ ). This leads to two congruent descriptions (e.g., Teacher/Anna; Engineer/Davide) and two incongruent descriptions (e.g., Engineer/Anna; Teacher/Davide) of the proposers. We assume that reading a stereotyped occupational role noun would lead to automatic and hard-to-suppress activation of the corresponding stereotype (Banaji and Hardin, 1996; Irmen and Roßberg, 2004; Oakhill et al., 2005; Reynolds et al., 2006; Gygax and Gabriel, 2008).

In line with previous results, we expect the nature of the offer to influence rejection rates with unfair offers refused more frequently than mid-value and fair offers. The picture may instead change if the proposers' biological gender and/or stereotypical gender modulate these default responses. Females are expected to be more generous and socially orientated than men who, in turn, are expected to be more selfish and individually orientated (Aguiar et al., 2009; Eckel and Grossman, 1998). Moreover, many female occupational roles and male occupational roles respectively produce expectations of communal traits (e.g., kindness, nurturance, welfare of others) and agentic traits (e.g., leadership qualities, competition, confidence; Eagly et al., 2000). These specific expectations may lead participants to predict they would receive higher incomes respectively from female proposers than from male proposers; and from female-stereotyped proposers than from male-stereotyped proposers. Because responders with high expectations are more likely to reject unfair offers compared to when they have low expectations (Sanfey, 2009), we predict that responders may turn down unfair shares more frequently when offered by respectively female proposers than male proposers; and by female-stereotyped proposers than by male-stereotyped proposers. Moreover, these predictions are in line with the results of Kubota et al. (2013) who found that the shares offered by low social status proposers are more likely to be rejected compared to the shares offered by high status proposers. Additionally, various studies in social psychology show that individuals who violate gender stereotypes may undergo social and economic penalties, a phenomenon called backlash effect (Rudman, 1998; Eagly and Karau, 2002; Phelan et al., 2008; Rudman and Phelan, 2008). We predict that the participants may be willing to penalize stereotype-incongruent proposers (e.g., Luisa/Ingegnere; Giogio/Insegnante) by rejecting their shares more frequently than the shares proposed by stereotype-congruent proposers (e.g., Luisa/Insegnante; Giorgio/Ingegnere).

As to the electrophysiological response, we expect to observe a greater negativity of the FRN in response to unfair and mid-value offers than to fair offers, as in previous studies (Polezzi et al., 2008; Wu et al., 2011, 2012; Alexopoulos et al., 2012, 2013; Qu et al., 2013). Since the FRN is thought to be sensitive to socio-emotional evaluation of the game partners (Campanhã et al., 2011; Qu et al., 2013) and to social expectancy violation (Boksem and DeCremer, 2010; Wu et al., 2012), we may observe greater FRN effects whenever social expectations are not met (Wu et al., 2011, 2012; Qu et al., 2013; Alexopoulos et al., 2013). Hence, the offers coming from stereotype-incongruent proposers, who violate gender rules, may be perceived as less fair and/or more negative. We predict to observe a greater FRN effect in response to shares offered by stereotype-incongruent proposers compared to stereotype-congruent proposers' offers, especially for unequal offers that are associated with a double violation of social norms (i.e., equity and gender rules). We expect the FRN to be followed by a P300 as previously found in various EEG studies (e.g., Wu et al., 2011, 2012; Qu et al., 2013). We predict to observe a greater P300 amplitude in response to complex offers (i.e., $3 €$ on $10 €$ ) compared to unfair (i.e., $1 €$ on 10 $€)$ and fair (i.e., $5 €$ on $10 €$ ) offers that are more easily categorized (Donchin and Coles, 1988; Verleger, 1988; Kok, 2001). Based on previous results (Wu et al., 2011, 2012; Qu et al., 2013), it is not clear how the proposers' identity (i.e., stereotypical gender and biological gender) would modulate the P300 amplitude. Nevertheless, since stereotype-congruent proposers may be categorized 
more easily compared to stereotype-incongruent proposers, we may observe a greater P300 amplitude for stereotype-congruent than for stereotype-incongruent proposers.

\section{Methods}

\subsection{Ethics statement}

All participants were informed of their rights and gave written informed consent for participation in the study, according to the Declaration of Helsinki. The research was carried out fulfilling ethical requirements in accordance with the standard procedures of the University of Modena and Reggio Emilia.

\subsection{Participants}

32 Italian students of Modena university ( 16 females, $M_{\text {Age }}=22$, $S D \pm 3.71$, age range 19-32 years old) participated in this study. all were right-handed as assessed by the Edinburgh handedness inventory (Oldfield, 1971) and had normal or corrected-to-normal vision. none of the participants reported a history of prior Neurological disorder. they participated for $5 \%$ of the total amount of money they won and were proposed only at the end of the experiment to swap it for a course credit.

\subsection{Materials}

\subsubsection{Norming phase}

In order to select the experimental materials, a written questionnaire listing 258 occupational role nouns (ending in -e, -ista or a consonant to avoid that word forms contained cues to the gender of the referent) was presented to 112 students not further involved in the experiment ( 56 females; age range $19-27$ years; $M_{\text {Age }}=23.6$, $S D \pm 2.92$ ). Eighty of these students rated to what extent each role noun was stereotypically associated with male or female individuals on a 7-point Likert scale (i.e., stereotype strength; from $1=$ only men to $7=$ only women), sixteen of them to what extent each role noun was associated with a positive or negative value (i.e., valence; from $1=$ very negative to $7=$ very positive) and sixteen the wealth of a person described with each role noun (i.e., wealth; from $1=$ very rich to $7=$ very poor). The labels of the scale poles were reversed for half of the participants. The final rating assigned to each word was calculated by combining the ratings obtained with both directions of each rating scale. The sixty role nouns selected as experimental materials received comparably high ratings of stereotypicality (the experimental material and the associated ratings are available in Supplementary material). In order to compare the stereotype strength of the two role noun groups, the ratings of the role nouns ranging from 4 to 7 (i.e., feminine stereotypes) were translated and ranged from 1 to 4 (i.e., $X^{\prime}=8-X$, with $X$ : initial rating and $X^{\prime}$ : translated rating). Stereotype strength (Female Stereotypes: $M=2.81, S D \pm 1.21$; Male Stereotypes: $M=2.77, S D \pm 1.19$ ), valence (Female Stereotypes: $M=4.42, S D \pm .69$; Male Stereotypes: $M=4.36, S D \pm .71$ ), wealth (Female Stereotypes: $M=3.81, S D \pm .94$; Male Stereotypes $M=4.10$, $S D \pm .88$ ), lexical frequency (Female Stereotypes: $M=5.66$, $S D \pm .87$; Male Stereotypes $M=6.09, S D \pm 1.05$ ) and length (i.e., number of characters; Female Stereotypes: $M=9.77, S D \pm 2.2$; Male Stereotypes $M=8.83, S D \pm 1.82$ ) of male and female occupational role nouns were comparable $(p s>.05)$. The stereotypicality mean rating of feminine role nouns reported in the Supplementary material table is the translated rating (i.e., $X^{\prime}$ ). Experimental materials also included 360 Italian familiar proper names (180 feminine). Unisex names were excluded from the list.

\subsection{Procedure}

Participants played a one-shot ultimatum game as responders. The instructions were presented in a written form before the experiment started. An introduction explaining the rules of the ultimatum game was given to each participant. Before conducting the game, participants were told that they were playing against 360 really existing different proposers of whom, they would know occupations and proper names and that each of them would offer to split $10 €$ once. The participant's task was to accept or reject each offer. Participants were explained that proposers took part to a previous experiment, and asked how much money they would have offered a student and that these offers were filled into the experiment's database used in the game. They were also told that the proposers that participated would be paid afterwards depending of their responses during the game (i.e., accept/reject). Participants were informed that at the end of the experiment, they would receive a payment, consisting of a percentage of the money they would have accepted during the game. At the end of the experiment, they were proposed to swap the money they won for course credits. Five of them chose to keep the money while the others swapped it for credit courses.

Participants were seated comfortably in a darkened sound-attenuated room. Stimuli were presented in white upper case letters (Courier font, size 14) against a black background on a high-resolution computer that was positioned at eye level $70 \mathrm{~cm}$ in front of the participant. A fixation point $(+)$ appeared in the middle of the screen and stayed there until participants pressed the space bar to start a trial. Then a blank screen was displayed for $300 \mathrm{~ms}$. Each role noun appeared for $700 \mathrm{~ms}$ followed by a proper name for $700 \mathrm{~ms}$ and then by the sentence "Ti propone" (Proposes you) for $700 \mathrm{~ms}$. Each presentation was followed by a blank screen for $300 \mathrm{~ms}$. Finally, the offer $(1 €, 3 €$, or $5 €)$ appeared and remained on the screen until the participant's response. Half of the participants pressed the response button marked with $M$ to accept and then one marked with $C$ to reject the offer. The other half did the reverse. Each response was followed by a 1000 ms blank screen.

Before starting the experiment, participants took part in a short training session consisting of 10 trials, different from those used in the experimental session. Each experimental session included 360 randomized trials [3 (Offer: unfair, mid-value, fair) $\times 2$ (Occupational Stereotype: female, male) $\times 2$ (Proposer's Gender: female, male) $\times 30$ repetitions], yielding a total of 90 offers for each proposer's description: two stereotype-congruent descriptions (e.g., Teacher-Anna; Engineer-Davide) and two stereotype-incongruent descriptions of proposers (e.g., Engineer-Anna; Teacher-Davide). Participants interacted only once with each proposer to avoid effects of reciprocity.

Lastly, because the strength of the stereotypical beliefs and empathy may vary among participants, we included a series of explicit post-experiment measures. At the end of the experiment, participants were asked to fill the Interpersonal Reactivity Index (IRI: perspective taking (pt) and empathic concern (ec) scales; Davis, 1980; Albiero et al., 2006), the Bem Sex Role Inventory (BSRI: masculine minus feminine score; Bem, 1974; De Leo and Villa, 1986), the Ambivalent Sexism Inventory (ASI: benevolent sexism (bs) and hostile sexism (hs) scales; Glick and Fiske, 1996; Manganelli et al., 2008) and the Ambivalence toward Men Inventory (AMI: positive traditional gender-power relations (bm) and hostility toward men scales (hm); Glick and Fiske, 1996; Manganelli et al., 2008).

\subsection{Data acquisition}

\subsubsection{Experimental apparatus}

The experimental paradigm was presented using E-Prime 2 
(Psychology Software Tools, Inc., Pittsburgh, PA) on a laboratory's computer. Participants were seated in a chair, with a headrest supporting the back of the head to minimize motion, and they viewed the paradigm on a computer monitor.

\subsubsection{Electroencephalograph (EEG) recordings}

EEG was amplified and recorded with a BioSemi ActiveTwo system from $30 \mathrm{Ag} / \mathrm{AgCl}$ active electrodes (http://www.biosemi. $\mathrm{com}$ ) mounted on a cap and placed on the scalp according to the International 10-20 System (FP1, FP2, AF3, AF4, F7, F3, Fz, F4, F8, FC5,FC1, FC2, FC6, CP5, CP1, Cz, CP2, CP6, P7, P3, Pz, P4, P8, T7, T8, PO3, P04, O1, Oz, O2) plus two sites below the eyes for eye movement monitoring. Two additional electrodes placed close to $\mathrm{Cz}$, the Common Mode Sense [CMS] active electrode and the Driven Right Leg [DRL] passive electrode, were used to form the feedback loop that drives the average potential of the participant as close as possible to the AD-box reference potential (Metting Van Rijn et al., 1990). Electrode impedance was kept below $5 \mathrm{k} \Omega$ for scalp electrodes, and below $10 \mathrm{k} \Omega$ for the four eye channels. Skinelectrode contact, obtained using electro-conductive gel, was monitored, keeping voltage offset from the CMS below $25 \mathrm{mV}$ for each measurement site. All the signals were (DC) amplified and digitalized continuously with a sampling rate of $512 \mathrm{~Hz}$ with an anti-aliasing filter with $3 \mathrm{~dB}$ point at $104 \mathrm{~Hz}$ (fifth order sinc filter); no high-pass filtering was applied online. The triggering signals to each word onset were recorded on additional digital channels. EEG data were off-line re-referenced to the average activity of the two mastoids and band-pass filtered $(.1-40 \mathrm{~Hz}, 12 \mathrm{~dB} /$ octave), given that for some subjects the low-pass filter was not effective in completely removing the $50-\mathrm{Hz}$ artifact. Epochs were time locked to the offer presentation and extracted in the interval from $-200 \mathrm{~ms}$ to $800 \mathrm{~ms}$. Data with excessive blinks were adaptively corrected using ICA. Segments including artefacts (such as excessive muscle activity) were eliminated off-line before data averaging. The lost data (due to artefacts) were equal to $8 \%$ A $100 \mathrm{~ms}$ pre-stimulus baseline was used in all analyses.

\subsection{Data analysis}

\subsubsection{Behavioral data}

Acceptance Rates. To account for the dichotomous nature of the dependent variable [the binary decision of accepting $=1$ or rejecting $=0$ an offer], we conducted a $3 \times 2 \times 2 \times 2$ (Offer [ $1 €, 3 €, 5$ $€$ ] $\times$ Participant's Gender [male, female] $\times$ Occupational Stereotype [male, female] $\times$ Proposer's Gender [male, female]) mixed model generalized binary logistic regression. Occupational stereotype and proposer's gender were implemented as random effects. A manual stepwise analysis was performed to remove non-significant interactions from the model. Contrasts between conditions were reported for significant effects.

Questionnaires. We conducted correlation analyses between the scores of the BSRI, the ASI, the AMI, the IRI, and the resultants of the differences in mean offer for (1) proposers characterized by female vs. male stereotypes, i.e., St (F-M), (2) female vs. male proposers, i.e., Gender (F-M), (3) female vs. male proposers characterized by female stereotype, i.e., StF [Gender (F-M)] and (4) male vs. female proposers characterized by male stereotypes, i.e., StM [Gender (M-F)].

Response times. Individual response times exceeding $\pm 2 S D$ were rejected. Because Shapiro-Wilk test revealed that all variables violated the normality assumption, a log transformation was realized on the response times. A $3 \times 2 \times 2 \times 2$ (Offer [ $1 €, 3 €, 5 €] \times$ Participant's Gender [male, female] $\times$ Occupational Stereotype [male, female] $\times$ Proposer's Gender [male, female]) analysis of variance (ANOVA) was conducted on the log-transformed mean response times of each participant, with offer, participant's gender, occupational stereotype and proposer's gender as within-subject factors, and participant's gender as between factor. LSD post hoc test were carried out to further examine significant effects ( $\alpha .05)$.

\subsubsection{Electrophysiological data}

Overall participants were presented with 30 trials per condition (360 trials in total). After removing the artefacts, each participants had on average 27.4 trials $(S D=2.1)$ per condition for EEG averaging. Based on a visual inspection of the waveforms, statistical analyses on mean amplitude values were carried out in the 220-280 ms and 280-410 ms time.

220-280 ms time window. The FRN amplitude was assessed in terms of mean amplitude at the Fz, FC1, FC2 and $\mathrm{Cz}$ electrode where FRN amplitudes were maximal in both the current study and in previous FRN studies (e.g., Miltner et al., 1997; Loehr et al., 2013). A $4 \times 3 \times 2 \times 2 \times 2$ (Electrode [Fz, FC1, FC2, Cz], Offer [1€, $3 €$, $5 €$ ] $\times$ Participant's Gender [male, female] $\times$ Occupational Stereotype [male, female] $\times$ Proposer's Gender [male, female]) ANOVA was conducted with electrode, offer, occupational stereotype and proposer's gender as within-subject factors and participant's gender as a between-subject factor. LSD were used for post-hoc contrasts.

280-410 ms time window. The amplitude of the P300 was assessed in terms of the mean amplitude in the $280-410 \mathrm{~ms}$ time window. In order to investigate possible topographical differences, mean voltage values were assessed at the midline electrodes (Bennington and Polich, 1999; Holm et al., 2006; Giraudet et al., 2015). A $3 \times 3 \times 2 \times 2 \times 2$ (Electrode [Fz, Cz, Pz] $\times$ Offer [1€, 3€, 5 $€$ ] $\times$ Participant's Gender [male, female] $\times$ Occupational Stereotype [male, female] $\times$ Proposer's Gender [male, female]) repeated measures ANOVA was conducted with electrode, occupational stereotype, proposer's gender and offer as within-subject factors and participant's gender as a between-subject factor.

\section{Results}

\subsection{Behavioral results}

\subsubsection{Acceptance rate}

The model classified correctly $81.8 \%$ of choices $(84.9 \%$ of acceptances and $77.2 \%$ of rejections). The offer factor $[F(2,60)=$ $1216.82, p<.001$; see Fig. $1 \mathrm{~A}$ ] was a significant predictor of choice. Participants accepted more frequently fair $(M=89.34 \%, S D \pm 13.89)$ than mid-value $(M=61.71 \%, S D \pm 30.32, p<.001)$ and unfair offers $(M=24.56 \%, S D \pm 30.13, p<.001)$, and more often mid-value than unfair offers $(p<.001$; see Fig. 1A). The occupational stereotype was a significant predictor as well $[F(1,30)=7.140 ; p<.01$; Fig. 1B]. Participants accepted more frequently offers coming from proposers characterized by female occupational $(M=61.01 \%$, $S D \pm 36.52)$ than by male occupational stereotypes $(M=56.07 \%$, $S D \pm 36.43$ ). Significant Offer $\times$ Participant's Gender and Offer $\times-$ Proposer's Gender interactions were obtained $[F(2,60)=9.035$, $p<.001 ; F(2,60)=69.09, p<.001$, respectively; see Fig. $1 C$ and $D]$. Participants accepted more frequently mid-value offers when offered by female $(M=63.11 \%, S D \pm 29.68)$ than by male proposers $(M=60.31 \%, S D \pm 30.88, p<.005)$. Male participants accepted more frequently both fair $(M=94.43 \%, S D \pm 10.45, p<.01)$ and mid-value offers $(M=67.41 \%, S D \pm 31.90, p<.01)$ than did female participants (5€: $M=84.25 \%, \quad S D \pm 15.81 ; \quad 3 €: \quad M=56.01 \%$, $S D \pm 27.76)$. No significant effects were found for the proposer's gender and the participant's gender factor [respectively, $F(1$, $30)=.012, p=.91 ; F(1,30)=.861, p=.353]$. The remaining interactions failed to reach significance and were removed from the model after a manual stepwise analysis. 

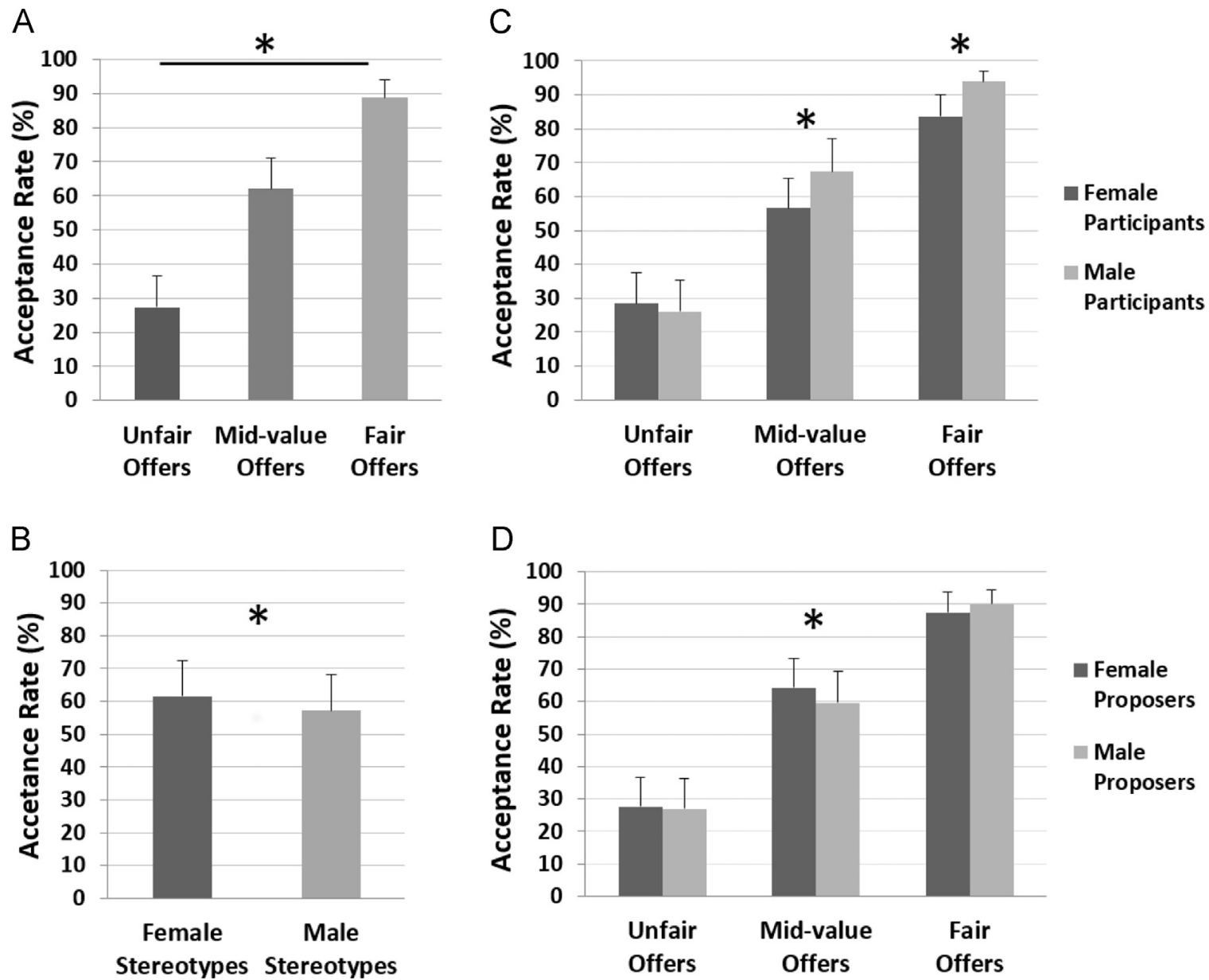

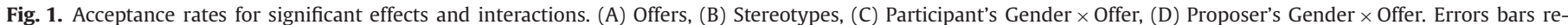
present standard errors.

\subsubsection{Questionnaires}

We comment only significant effects of interest (see Table 1 for a summary of statistical analyses). The score of the BSRI was negatively correlated to the St (F-M), the Gender (F-M) and the StF [Gender (F-M)] differences in mean offer [respectively: $r$
$(30)=-.484, \quad p<.01 ; \quad r(30)=-.363, \quad p<.05 ; \quad r(30)=-.334$, $p<.05]$. For the participants, a majority of male characteristics (i.e., high BSRI score) predicted higher acceptance rates for the shares offered by female-stereotyped than by male stereotyped proposers and, by female than male proposers characterized by a

Table 1

Correlations between the questionnaires' scores and the differences in acceptance rates.

\begin{tabular}{|c|c|c|c|c|c|c|c|c|c|c|c|}
\hline & \multicolumn{7}{|c|}{ Questionnaires } & \multicolumn{4}{|c|}{ Difference in acception rate } \\
\hline & BSRI & ASI (bs) & ASI (hs) & AMI (bm) & AMI (hm) & IRI (pt) & IRI (ce) & $\begin{array}{l}\text { Stereotype (F- } \\
\text { M) }\end{array}$ & $\begin{array}{l}\text { Gender (F- } \\
\mathrm{M})\end{array}$ & $\begin{array}{l}\text { Stereotype F [Gender } \\
(\mathrm{F}-\mathrm{M})]\end{array}$ & $\begin{array}{l}\text { Stereotype M [Gender } \\
(\mathrm{M}-\mathrm{F})]\end{array}$ \\
\hline \multicolumn{12}{|l|}{ Questionnaires } \\
\hline BSRI & - & .235 & $.461^{* *}$ & $.516^{* *}$ & -.010 & -.252 & $-.383^{*}$ & $-.484^{* *}$ & $-.363^{*}$ & $-.334^{*}$ & .112 \\
\hline ASI (bs) & .235 & - & .277 & $.698^{* * *}$ & $.606^{* *}$ & -.175 & .212 & -.165 & .196 & -.083 & $-.336^{*}$ \\
\hline ASI (hs) & $.461^{* *}$ & .277 & - & $.577^{* *}$ & .239 & -.160 & $-.484^{* *}$ & -.180 & .027 & -.170 & -.230 \\
\hline AMI (bm) & $.516^{* *}$ & $.698^{* *}$ & $.577^{* * *}$ & - & $.471^{* *}$ & -.323 & -.176 & -.247 & -.041 & -.310 & -.288 \\
\hline AMI (hm) & -.010 & $.606^{* *}$ & .239 & $.471^{* *}$ & - & $-.357^{*}$ & .170 & .162 & .227 & -.084 & $-.363^{*}$ \\
\hline IRI (pt) & -.252 & -.175 & -.160 & -.323 & $-.357^{*}$ & - & $.541^{* * *}$ & .125 & -.058 & -.026 & .040 \\
\hline IRI (ce) & $-.383^{*}$ & .212 & $-.484^{* *}$ & -.176 & .170 & $.541^{* *}$ & - & .254 & .049 & .035 & -.012 \\
\hline \multicolumn{12}{|c|}{ Differences in acceptation rates } \\
\hline Stereotype (F-M) & $-.484^{* *}$ & -.165 & -.180 & -.247 & .162 & .125 & .254 & - & .311 & .226 & -.175 \\
\hline Gender (F-M) & $-.363^{*}$ & .196 & .027 & -.041 & .227 & -.058 & .049 & .311 & - & $.670^{* *}$ & $-.645^{* *}$ \\
\hline $\begin{array}{l}\text { StF[Gender (F- } \\
\quad \mathbf{M})]\end{array}$ & $-.334^{*}$ & -.083 & -.170 & -.310 & -.084 & -.026 & .035 & .226 & $.670^{* *}$ & - & .125 \\
\hline $\begin{array}{l}\text { StM[Gender (M- } \\
\text { F)] }\end{array}$ & .112 & $-.336^{*}$ & -.230 & -.288 & $-.363^{*}$ & .040 & -.012 & -.175 & $-.645^{* *}$ & .125 & - \\
\hline
\end{tabular}

${ }^{*} p<.05$. 

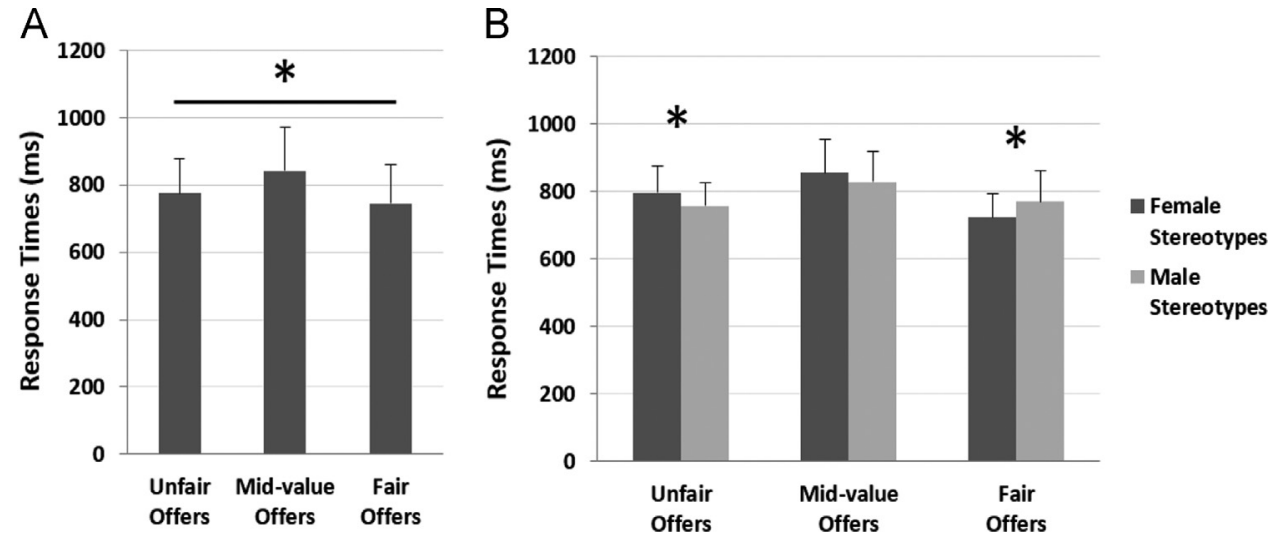

Fig. 2. Response times for (A) Offers, (B) Offer by Stereotype. Errors bars represent standard errors.

A

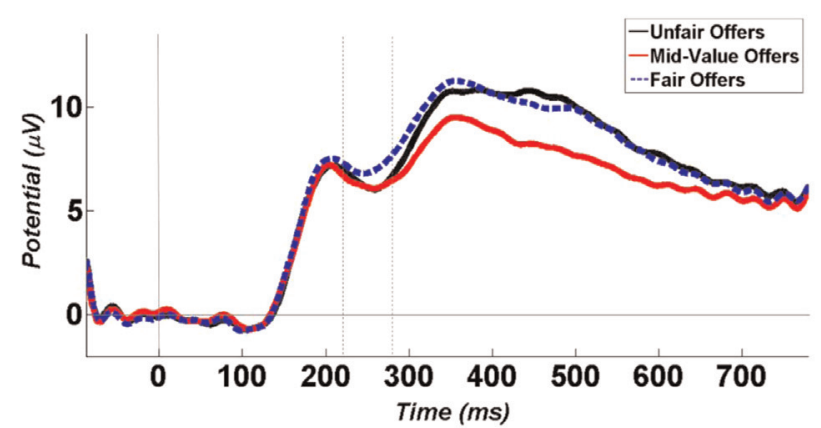

B

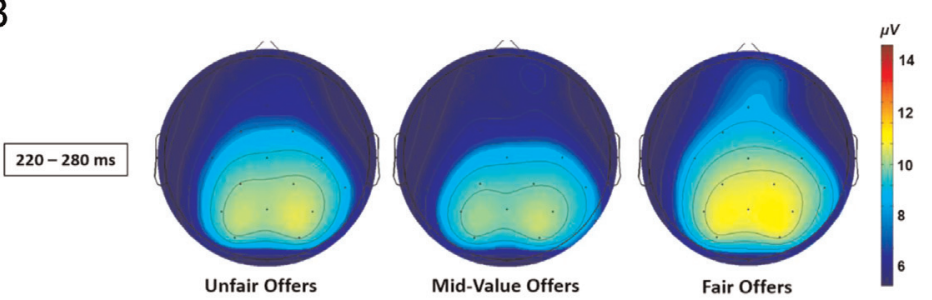

C
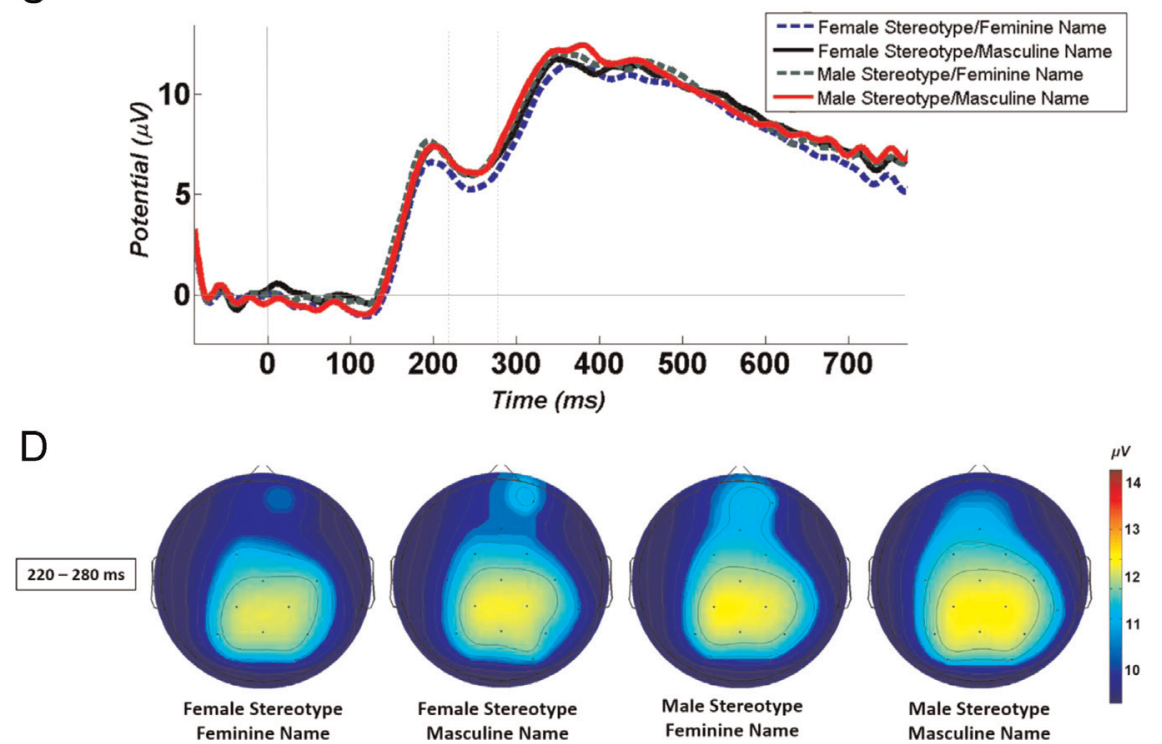

Fig. 3. Grand average ERP waveforms at the region of interest (i.e., Fz, FC1, FC2 and Cz merged; A and C) and scalp potentials topographies (B and D) for offers and the proposers' identity for the time point of the FRN (220-280 ms following offer onset). (A) Offers: fair offers (black line), mid-value offers (red line) and unfair offers (dotted blue line); (C) Proposers' identity: Female Proposer characterized by a Female Stereotype (dotted blue line), Female Proposer characterized by a Male Stereotype (black line), Male Proposer characterized by a Female Stereotype (dotted green line) and Male Proposer characterized by a Male Stereotype (red line). Negative is plotted down; zeros on the timelines indicate the onset of the offer. Scalp potentials topographies (B and D) show greater negativities at frontal central sites. The P300 component is already starting to emerge at parietal sites. (For interpretation of the references to color in this figure legend, the reader is referred to the web version of this article.) 
male stereotype. While a majority of female characteristics (i.e., low BRSI score) predicted the opposite pattern of results. The StM (M-F) difference in mean offer was also negatively correlated to the ASI (bs) score and the AMI (hm) score [respectively: $r$ $(30)=-.336, p<.05 ; r(30)=-.363, p<.05]$. High scores on benevolent sexism toward women and hostile sexism toward men

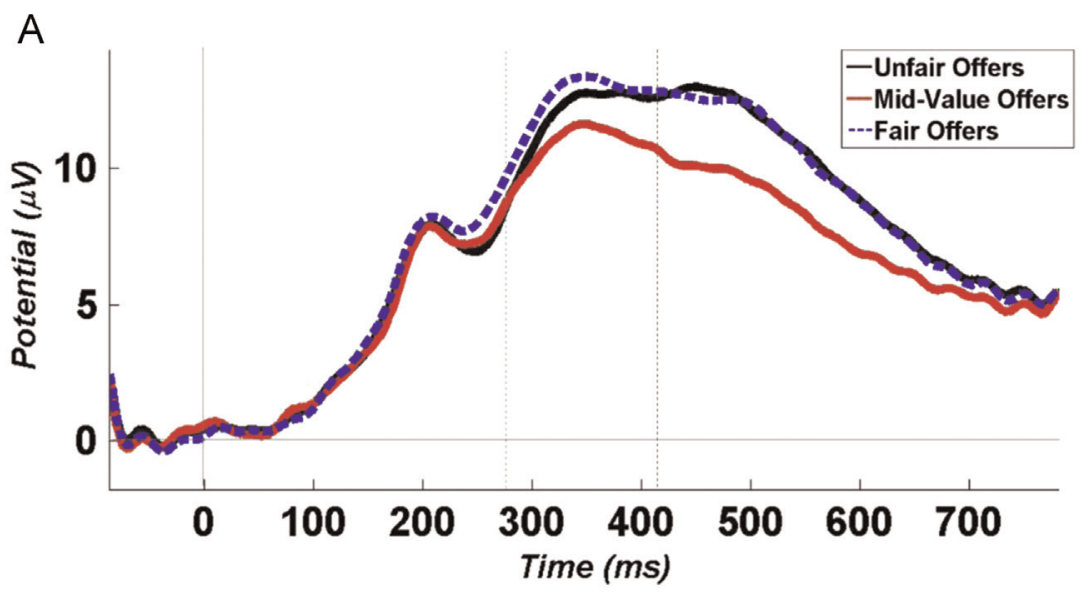

B
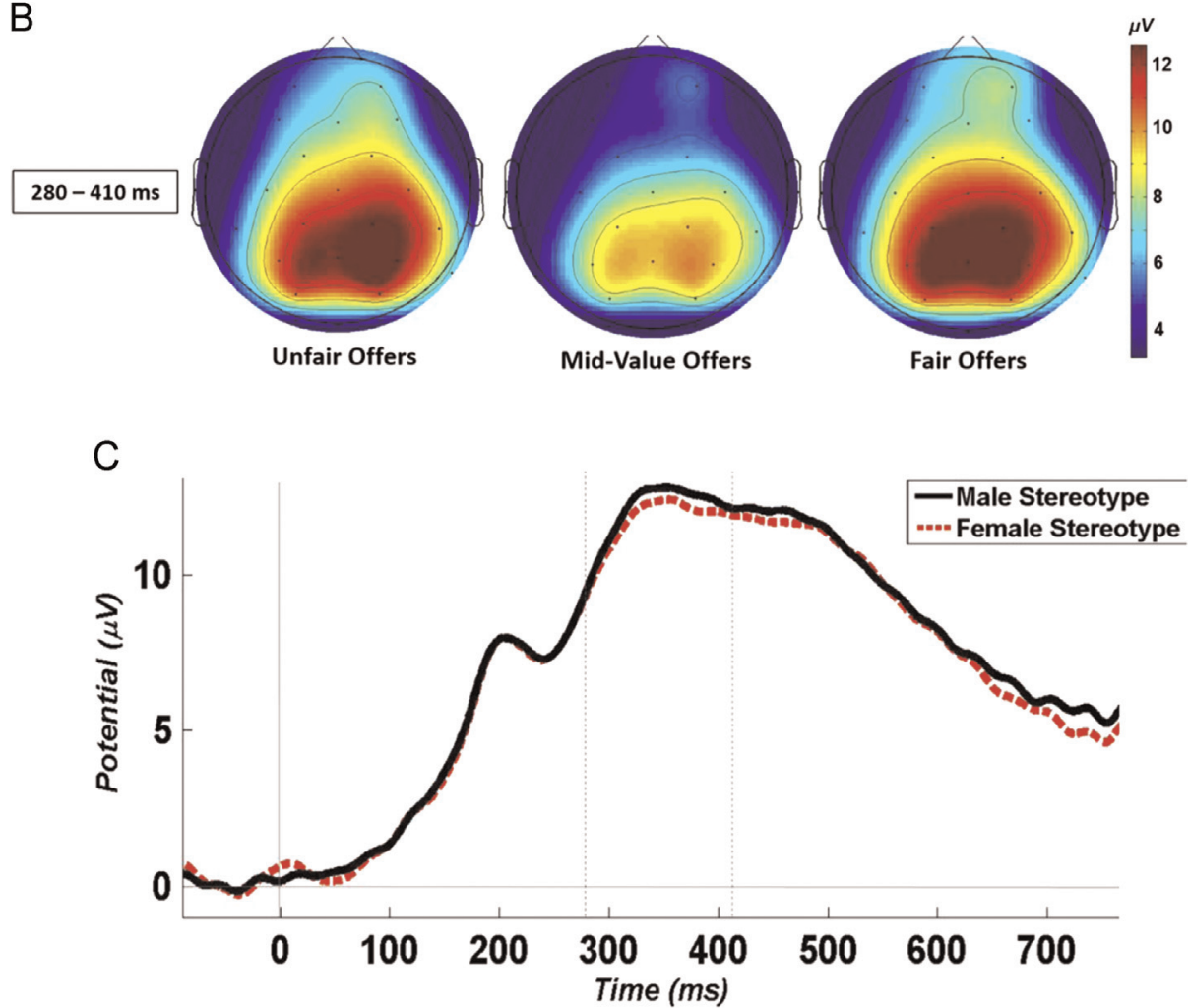

D
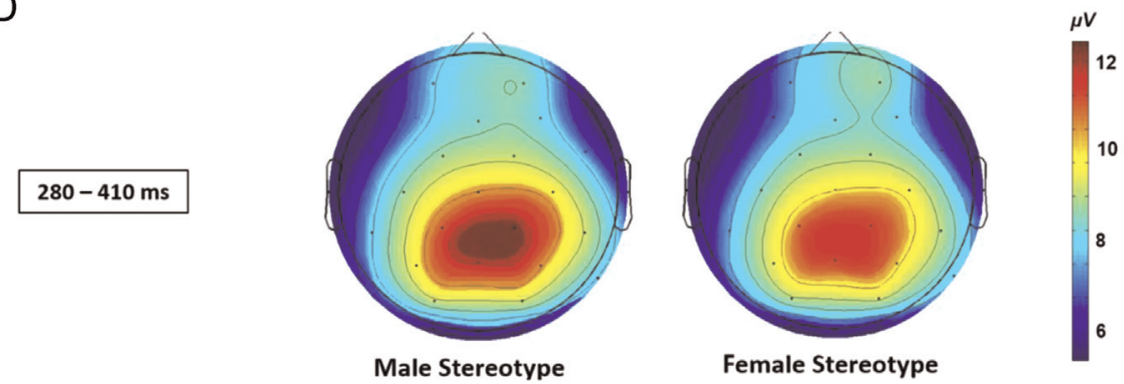

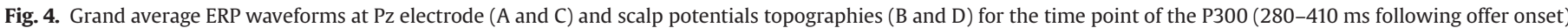

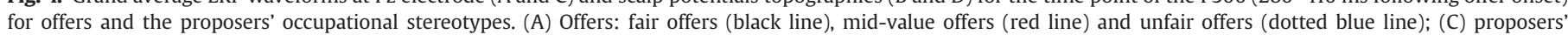

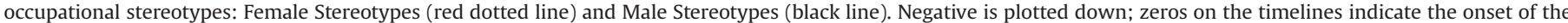
offer. (For interpretation of the references to color in this figure legend, the reader is referred to the web version of this article.) 
predicted higher acceptance rates for female than male proposers characterized by male occupational stereotypes while low scores predicted the opposite pattern.

\subsubsection{Response times}

We comment only significant effects (see Supplementary material for a summary of statistical analyses). We obtained a significant main effect of offer $[F(2,30)=11.36, p<.001, \eta p 2=.27$; see Fig. 2A] with longer response times to mid-value $(M=841 \mathrm{~ms}$, $S D \pm 369)$ than to unfair $(M=776 \mathrm{~ms}, S D \pm 289, p<.05)$ and fair $(M=746 \mathrm{~ms}, S D \pm 322, p<.001)$ offers, and to unfair than fair offers $(p<.05)$. A significant Offer $\times$ Occupational Stereotype interaction was found $[F(2,60)=6.20, p<.005, \eta p 2=.17$; see Fig. $2 B]$. Participants were also faster in responding to fair offers $(M=722 \mathrm{~ms}, S D \pm 289)$ than to unfair offers $(M=795 \mathrm{~ms}, S D \pm 317$, $p<.001$ ) when proposers were characterized by female occupational stereotypes. They were also faster responding to unfair offers when proposed by male-stereotyped proposers than by female-stereotyped proposers (respectively $M=756 \mathrm{~ms}, S D \pm 270$; $M=794 \mathrm{~ms}, S D \pm 317, p<.05$ ), and to fair offers when coming from proposers with female than male occupational stereotypes (respectively $M=722 \mathrm{~ms}, S D \pm 289 ; M=769 \mathrm{~ms}, S D \pm 360, p<.05$ ).

\subsection{Electrophysiological results}

\subsubsection{0-280 ms time windows}

We obtained a significant main effect of offer $[F(2,60)=3.64$, $p<.05, \eta p 2=.11$; see Supplementary material for a summary of the statistics] in that unfair $(M=6.35 \mu \mathrm{V}, S D \pm 5.09)$ and mid-value $(M=6.24 \mu \mathrm{V}, S D \pm 4.68)$ offers generated a significantly greater negativity than fair offers $(M=7.04 \mu \mathrm{V}, S D \pm 5.26, p<.05$ in both cases; see Fig. 3A and B). No difference was found for unfair offers and mid-value offers $(p=.72)$. We also observed a significant Occupational Stereotype $\times$ Proposers' Gender $\times$ Participant's Gender interaction $[F(1,30)=7.05, p<.01, \eta p 2=.19$; see Fig. $3 C$ and D]. A greater negativity occurred in male participants when female proposers were characterized by feminine occupational stereotypes $(M=5.92 \mu \mathrm{V}, S D \pm 4.66)$ than by masculine occupational stereotypes on one hand $(M=6.98 \mu \mathrm{V}, S D \pm 4.88, p<.05)$ and on another hand, than male proposers in general (female occupational stereotype: $M=6.89 \mu \mathrm{V}, S D \pm 4.32, p<.05$; male occupational stereotype: $M=6.94 \mu \mathrm{V}, S D \pm 4.60, p<.05)$.

\subsection{2. $280-410 \mathrm{~ms}$ time window}

The analysis revealed a significant main effect of offer $[F(2$, $60)=9.47, p<.001, \eta p 2=.24$; see Fig. $4 \mathrm{~A}$ and $\mathrm{B}$ ] with a greater positivity for fair $(M=11.19 \mu \mathrm{V}, S D \pm 5.82, p<.001)$ and unfair offers $(M=10.61 \mu \mathrm{V}, S D \pm 5.25, p<.01)$ than for mid-value offers $(M=9.41 \mu \mathrm{V}, S D \pm 4.66)$. We observed an Electrode $\times$ Occupational Stereotype significant interaction $[F(2,60)=3.21, p<.05, \eta p 2=.10$; see Fig. 4C and D]. We obtained a significant greater positivity when proposers were presented with male (Fz: $M=8.96 \mu \mathrm{V}$, $S D \pm 6.15 ; C z: M=10.97 \mu \mathrm{V}, S D \pm 6.40 ; \mathrm{Pz}: M=12.07 \mu \mathrm{V}, S D \pm 6.17)$ than female occupational stereotypes on each of the three electrodes (Fz: $M=8.37 \mu \mathrm{V}, S D \pm 5.66, p<.001 ; \mathrm{Cz}: M=10.35 \mu \mathrm{V}$, $S D \pm 5.78, p<.001$; Pz: $M=11.69 \mu \mathrm{V}, S D \pm 5.55, p<.001)$. Finally, the statistical analysis also revealed a significant Electrode $\times$ Occupational Stereotype $\times$ Participant's Gender $[F(2,60)=$ $3.21, p<.05, \eta p 2=.10]$. Post hoc analysis revealed no effect of interest. No other significant result was found (see Supplementary material for a summary of statistical analyses).

\section{Discussion}

The main aim of the present study was to investigate how gender stereotypes affect fairness consideration in the ultimatum game and the associated ERP components (i.e., FRN and the P300). In line with literature, behavioral results showed that participants rejected more frequently unfair offers than mid-value offers than fair offers. This result once again confirms the willingness of responders to sacrifice their own economic interest to punish unfair behaviors (Thaler, 1988; Camerer, 2003). At an electrophysiological level, we observed a more negative FRN in response to non-equal offers (i.e., unfair and mid-value offers) than to equal offers (in line with Polezzi et al., 2008; Alexopoulos et al., 2012, 2013; Wu et al., 2011, 2012; Qu et al., 2013). In various decision-making studies, the FRN, thought to be generated by the ACC (Gehring and Willoughby, 2002; Holroyd and Coles, 2002), has been found to reflect conflict detection/monitoring (Carter et al., 1998; Botvinick et al., 2001; Yeung et al., 2004; De Neys and Glumicic, 2008; Achtziger et al., 2012). Moreover, Sanfey et al. (2003) found a greater activity of the ACC in response to non-equal offers (i.e., ranging from $10 \%$ to $30 \%$ of the share) and interpreted this activity to reflect conflict detection (Botvinick et al., 1999; MacDonald et al., 2000). For equal offers, the strategic rule (i.e., accepting every offer to maximize the gain) and the cognitive heuristic (i.e., rejecting only non-equal offers) concur with each other. However, answering non-equal offers is contentious in that one has to choose to follow either the strategic rule or the cognitive heuristic. Then, we assume that in the ultimatum game, the FRN reflects the detection/monitoring of the conflict (Gehring and Fencsik, 2001) between the strategic rule and the cognitive heuristic. This interpretation is concordant with the results of Achtziger et al. (2012) who found a greater FRN amplitude when the (representative) heuristic conflicted with the normative strategy (e.g., Bayesian updating).

Behavioral results also showed that participants were faster in answering both fair and unfair offers than mid-value offers. We assume that both unfair offers and fair offers were automatically classified and processed relying on cognitive heuristics (system 1; Civai, 2013). However, because mid-value offers are not completely unfair and participants had to maximize their final outcome, they were more motivated to make their decision on mid-value offers based on a deliberative reasoning (i.e., system 2; Sanfey and Chang, 2008; Civai, 2013). At an electrophysiological level, a greater P3b amplitude was observed in response to both fair and unfair offers compared to mid-value offers. The P3b component is known to reflect the promotion of working memory operations and categorization processes (Donchin and Coles, 1988; Verleger, 1988; Kok, 2001) in temporal-parietal areas (Polich, 2007). We assume that the increase in $\mathrm{P} 3 \mathrm{~b}$ amplitude reflects the association of the offers processed automatically (i.e., unfair and fair offers) with the corresponding heuristics maintained in working memory (Khader et al., 2011). While the lower P3b amplitude observed for mid-value offers may reflect the disruption of the association with the cognitive heuristic triggered by the switch to a costly deliberative decision-making (i.e., system 2 ).

Behavioral results also revealed that participants made their decisions according not only the offers nature but also the proposers' stereotypical identity. Indeed, participants were more likely to accept the shares when proposed by female-stereotyped proposers than by male-stereotyped proposers. They were also longer in answering unfair offers when offered by female-stereotyped proposers than by male-stereotyped proposers. At an electrophysiological level, a decreased P3b amplitude was observed in response to the shares offered by female-stereotyped proposers compared to those offered to male-stereotyped proposers. As for mid-value offers, this decrease in P3b amplitude may reflect the switch to a costly deliberative decision-making (i.e., system 2) when playing with female-stereotyped proposers. Regardless of the fact that male-stereotyped role nouns and female-stereotyped role nouns had comparable ratings on both wealth and valence, female-stereotyped proposers may have been perceived as less 
powerful and socially weaker compared to male-stereotyped proposers (Eagly, 1987; Conway et al., 1996; Ridgeway, 2001). This may have induced more positive and emphatic feelings toward female-stereotyped proposers (Eckel and Grossman, 2001), motivating the participants to engage in a costly deliberative reasoning (i.e., system 2). As a result, the shares offered by female-stereotyped proposers were accepted more frequently than those offered by male-stereotyped proposers.

The gender of the proposers was found to modulate the decision of the participants but only when they were proposed midvalue offers. Indeed, participants were more likely to accept midvalue offers when the proposers were female than when they were male. Like female-stereotyped proposers, female proposers may have triggered more positive and emphatic feelings in the participants (Eckel and Grossman, 2001). For this reason, playing with female proposers may have motivated the participants even more to reason deliberately (i.e., system 2), but only when they were proposed mid-value offers (i.e., the more complex to deal with). However, this result was not reflected in the electrophysiological activity.

In contrast with our predictions, the acceptation rates associated with the shares offered by stereotype-incongruent proposers and those offered by stereotype-congruent proposers were not significantly different (i.e., no backlash effect). However, at an electrophysiological level, the FRN amplitude was diversely modulated according to the proposers' identity (i.e., both gender and occupational stereotype) but only in male participants, with a greater FRN amplitude observed in response to the offers proposed by female stereotype-congruent proposers (e.g., insegnante/Luisa) compared to the three other conditions. Because they share few social characteristics (i.e., gender and occupational stereotype) with them, female proposers characterized by female occupational stereotypes may be considered as out-group individuals by male responders (Ames et al., 2012). It is then very likely that male responders judged female proposers characterized by female occupational stereotypes according to their stereotype (i.e., stigmatization; Ames et al., 2012). Greater activity of the ACC known for yielding the FRN was also shown to reflect the attempt to inhibit stigmatization (Richeson et al., 2003; Cunningham et al., 2004; Lieberman et al., 2005). To this extent, we assume that the increase in FRN amplitude observed in male participants when playing with female proposers characterized by female occupational stereotypes may reflect the conflict between implemented behaviors based on stereotypical beliefs (i.e., discrimination of out-group individuals) and the strategic rule (i.e., accepting every offer to maximize the gain independently of the proposers' identity).

\section{Conclusion}

In the present study, we investigated to what extent the stereotypical description of the proposers affected the decisionmaking of responders playing the ultimatum game and the amplitudes of both the FRN and the P300. Our results support the assumption of Civai (2013) and Sanfey and Chang (2008), according to which responders playing the ultimatum game may rely on a dual-process system to make their decisions. Indeed, responders appear to have followed cognitive heuristics and answered both fair and unfair offers quite automatically (i.e., system 1 ), while they were willing to adopt a more costly and deliberative reasoning (i.e., system 2 ) to make their decision on mid-value offers. Participants also discriminated positively female-stereotyped proposers in that they were more likely to accept their offers compared to those offered by male-stereotyped proposers. More positive and emphatic feelings toward female-stereotyped proposers may have motivated participants to reason more deliberatively with these proposers than with male-stereotyped proposers. To this extent, the rejection of an offer may not occur only because it is not fair but also because the responders are not motivated enough by the proposers' stereotypical identity to make a supplementary effort to reason deliberatively and fight the rejection heuristic (i.e., system 1). This result demonstrates that people with an occupation stereotypically marked with female gender and engaged in an economic negotiation may benefit from their occupation at least in the case their counterparts lose their money if the negotiation fails.

We also propose new insights concerning the functional interpretation of both the FRN and the P3b in the ultimatum game that may reflect two different steps of the decision process. On one hand, a greater FRN amplitude may reflect the detection of contentious situations both economically and socially. Economically, when the strategic rule enters in conflict with a cognitive heuristic (i.e., rejecting unequal offers), and socially, when the same strategic rule enters in conflict with implemented behaviors based on stereotypical beliefs (i.e., discrimination of out-group individuals). On another hand, a greater P3b amplitude - observed in response to both unfair and fair offers and the shares offered by male-stereotyped proposers - may reflect the association of an offer with the corresponding heuristic stored in working memory, which may underpin an automatic heuristic-based decision-making (i.e., system 1). However, a lower P3b amplitude - observed in response to mid-value offers and the shares offered by female-stereotyped proposers - may reflect the responders' greater motivation to counter system 1 at a cognitive cost and to rely on a deliberative reasoning (i.e., system 2 ). As far as we know, the present study is the first to demonstrate that the FRN and the P300 components reflect the dual-process system operation in the ultimatum game and that both the offers nature and the stereotypical identity of the proposers can modulate the way this decision system operates.

Because the experimentation lasted for a long time (i.e., more than one hour and a quarter), we were not able to include $2 €$ and 4 $€$ offers to our experimental design. However, one question remains regarding these offers. Are they processed automatically based on system 1 like unfair and fair offers or more deliberatively based on system 2 like mid-value offers? A second fundamental question should be answered in a near future. Is it possible to manipulate the dual-process system? Indeed, what would happen if responders were proposed only offers ranging from $10 \%$ to $30 \%$ of the share (i.e., $1 €, 2 €$ and $3 €)$ ? Would mid-value offers (i.e., $3 €$ on $10 €$ ) still be processed deliberatively (i.e., system 2) or would they be automatically accepted (i.e., system 1 ) because they are the highest shares the responders can get? We plan to address these issues in future researches.

\section{Appendix A. Supplementary material}

Supplementary data associated with this article can be found in the online version at http://dx.doi.org/10.1016/j.neuropsychologia. 2015.06.013.

\section{References}

Achtziger, A., Bayer, U.C., Gollwitzer, P.M., 2012. Committing to implementation intentions: attention and memory effects for selected situational cues. Motiv. Emot. 36, 287-300. http://dx.doi.org/10.1007/s1103101192616.

Aguiar, F., Branas-Garza, P., Cobo-Reyes, R., Jimenez, N., Miller, L.M., 2009. Are women expected to be more generous? Exp. Econ. 12, 93-98. http://dx.doi.org $10.1007 / \mathrm{s} 106830089199 \mathrm{z}$

Albiero, P., Ingoglia, S., Lo Coco, A., 2006. A contribution to the Italian validation of the Interpersonal Reactivity Index. Test. Psicometria Metodol. 13, 107-125.

Alexopoulos, J., Pfabigan, D.M., Lamm, C., Bauer, H., Fischmeister, F.P., 2012. Do we care about the powerless third. An ERP study of the three-person ultimatum 
game. Front. Hum. Neurosci. 6, 59. http://dx.doi.org/10.3389/ fnhum.2012.00059.

Alexopoulos, J., Pfabigan, D.M., Göschl, F., Bauer, H., Fischmeister, F.Ph.S., 2013. Agency matters! Social preferences in the three-person ultimatum game. Front. Hum. Neurosci. 7, 312. http://dx.doi.org/10.3389/fnhum.2013.00312.

Ames, D.R., Mor, S., Toma, C., 2012. The double-edge of similarity and difference mindsets: What comparison mindsets do depends on whether self or group representation are focal. J. Exp. Soc. Psychol. 49 (3), 583-587. http://dx.doi.org 10.1016/j.jesp.2012.10.006.

Amiez, C., Joseph, J.P., Procyk, E., 2005. Anterior cingulate error-related activity is modulated by predicted reward. Eur. J. Neurosci. 21, 3447-3452, doi: 10.1111 j.14609568.2005.04170.x.

Banaji, M., Hardin, C., 1996. Automatic stereotyping. Psychol. Sci. 7, 136-141. http: //dx.doi.org/10.1111/j.14679280.1996.tb00346.x.

Bartholow, B.D., Amodio, D.M., 2009. Using event-related brain potentials in socia psychological research: a brief review and tutorial. In: Harmon-Jones, Eddie, Beer, Jennifer S. (Ed). Methods in Social Neuroscience. Guilford Press, New York, NY, US, xiv, pp. 198-232, 353 pp.

Bem, S.L., 1974. The measurement of psychological androgyny. J. Consult. Clin. Psychol. 42, 155-162. http://dx.doi.org/10.1037/h0036215.

Bennington, J.Y., Polich, J., 1999. Comparison of P300 from passive and active tasks for auditory and visual stimuli. Int. J. Psychophysiol. 34 (2), 171-177. http://dx. doi.org/10.1016/S01678760(99)000707.

Boksem, M.A., DeCremer, D., 2010. Fairness concerns predict medial frontal negativity amplitude in ultimatum bargaining. Soc. Neurosci. 5, 118-128. http://dx doi.org/10.1080/17470910903202666.

Botvinick, M.M., Nystrom, L.E., Fissell, K., Carter, C.S., Cohen, J.D., 1999. Conflict monitoring versus selection-for-action in anterior cingulated cortex. Nature 402, 179-181 10. 1038/46035.

Botvinick, M.M., Braver, T.S., Barch, D.M., Carter, C.S., Cohen, J.D., 2001. Conflict monitoring and cognitive control. Psychol. Rev. 103, 624-652 10 1037// $0033.295 X 108.3624$.

Brown, J.W., Braver, T.S., 2005. Learned predictions of error likelihood in the anterior cingulate cortex. Science 307 (5712), 1118-1121. http://dx.doi.org/ 10.1126/science.1105783.

Cacciari, C., Padovani, R., 2007. Further evidence of gender stereotype priming in language: semantic facilitation and inhibition in Italian role nouns. Appl. Psycholinguist. 28, 277-293. http://dx.doi.org/10.1017/S014271640707014.

Camerer, C., Thaler, R.H., 1995. Anomalies, ultimatums, dictators and manners. J. Econ. Perspect. 9 (2), 209-219. http://dx.doi.org/10.1257/jep.9.2.209.

Camerer, C., 1999. Behavioral economics: reunifying psychology and economics. Proc. Natl. Acad. Sci. 96, 10575-10577. http://dx.doi.org/10.1073/ pnas.96.19.10575.

Camerer, C., 2003. Behavioral Game Theory: Experiments in Strategic Interaction. Princeton University Press, Princeton, NJhttp://dx.doi.org/10.1257/jep.9.2.209.

Campanhã, C., Minati, L., Fregni, F., Boggio, P.S., 2011. Responding to unfair offers made by a friend: neuroelectrical activity changes in the anterior medial prefrontal cortex. J. Neurosci. 31 (43), 15569-15574. http://dx.doi.org/10.1523/ JNEUROSCI.1253-11.2011.

Carter, C.S., Braver, T.S., Barch, D.M., Botvinick, M.M., Noll, D., Cohen, J.D., 1998. Anterior cingulate cortex, error detection, and the online monitoring of performance. Science 280, 747-749. http://dx.doi.org/10.1126/ science.280.5364.747.

Civai, C., Corradi-Dell'Acqua, C., Gamer, M., Rumiati, R.I., 2010. Are irrational reactions to unfairness truly emotionally-driven? Dissociated behavioural and emotional responses in the ultimatum game task. Cognition 114, 89-95. http: //dx.doi.org/10.1016/j.cognition.2009.09.001.

Civai, C., 2013. Rejecting unfairness: emotion-driven reaction or cognitive heuristic? Front. Hum. Neurosci. 7, doi: 126.10.3389/fnhum.2013.00126.

Conway, M., Pizzamiglio, M.T., Mount, L., 1996. Status, communality and agency: Implications for stereotypes of gender and other groups. J. Personal. Soc. Psychol. 71 (1), 25-38. http://dx.doi.org/10.1037/00223514.71.1.25.

Corradi-Dell'Acqua, C., Civai, C., Rumiati, R.I., Fink, G.R., 2013. Disentangling selfand fairness-related neural mechanisms involved in the ultimatum game: an fMRI study. Soc. Cogn. Affect. Neurosci. 8 (4), 424-431. http://dx.doi.org/ $10.1093 /$ scan/nss014

Cunningham, W.A., Nezlek, J.B., Banaji, M.R., 2004. Implicit and explicit ethnocentrism: revisiting the ideologies of prejudice. Personal. Soc. Psychol. Bull. 30, 1332-1346. http://dx.doi.org/10.1177/0146167204264654.

Davis, M.H., 1980. A multidimensional approach to individual differences in empathy. JSAS Cat. Sel. Doc. Psychol. 10, 85.

De Leo, D., Villa, A., 1986. Il problema del rilevamento delle tipologie sessuali e il Bem Sex Role Inventory, Organ. Spec.

De Neys, W., Glumicic, T., 2008. Conflict monitoring in dual process theories of thinking. Cognition 106, 1248-1299. http://dx.doi.org/10.1016/j. cognition.2007.06.002.

De Quervain, D.J., Fischbacher, U., Treyer, V., Schellhammer, M., Schnyder, U., Buck A., Fehr, E., 2004. The neural basis of altruistic punishment. Science 305 (5688) 1254-1258. http://dx.doi.org/10.1126/science.1100735.

Donchin, E., Coles, M.G.H., 1988. Is the P300 component a manifestation of context updating? Behav. Brain Sci. 11, 357-374. http://dx.doi.org/10.1017/ S0140525 × 00058027.

Eagly, A.H., 1987. Sex differences in social behavior: a social-role interpretation. Erlbaum, Hillsdale, NJ.

Eagly, A.H., Wood, W., Diekman, A.B., 2000. Social Role Theory of Sex Differences and Similarities: A Current Appraisal. The Developmental Social Psychology of
Gender, pp. 123-174.

Eagly, A.H., Karau, S.J., 2002. Role congruity theory of prejudice toward female leaders. Psychol. Rev. 109, 573-598. http://dx.doi.org/10.1037/ 0033295X.109.3.573.

Eckel, C.C., Grossman, P.J., 1998. Are women less selfish than men? Evidence from dictator experiments. Econ. J. 108, 726-735. http://dx.doi.org/10.1111/ 14680297.00311

Eckel, C.C., Grossman, P.J., 2001. Chivalry and solidarity in ultimatum games. Econ. Inquiry 39 (2), 171-188. http://dx.doi.org/10.1111/j.1465-7295.2001.tb00059.x.

Falk, A., Fischbacher, U., 2006. A theory of reciprocity. Games Econ. Behav. 54 (2), 293-315. http://dx.doi.org/10.1016/j.geb.2005.03.001.

Fehr, E., Schmidt, K.M., 1999. A theory of fairness, competition, and cooperation. Q. J. Econ. 114 (3), 817-868.

Fehr, E., Gächter, S., 2002. Altruistic punishment in humans. Nature 415, 137-140. http://dx.doi.org/10.1038/415137a.

Fehr, E., Schmidt, K.M. 2005. The Economics of Fairness, Reciprocity and Altruism Experimental Evidence and New Theories. Discussion Paper No. 66. Chapter written for the Handbook on Reciprocity, Gift-Gving and Altruism. Department of Economics, University of Mannheim, Mannheim.

Folstein, J.R., Van Petten, C., 2008. Influence of cognitive control and mismatch on the N2 component of the ERP. A review. Psychophysiology 45, 152-170. http: //dx.doi.org/10.1111/j.14698986.2007.00602.x.

Frith, C.D., Singer, T., 2008. The role of social cognition in decision making. Philos. Trans. R. Soc. Lond. 363 (1511), 3875-3886. http://dx.doi.org/10.1098/ rstb.2008.0156.

Gaertig, C., Moser, A., Alguacil, S., Ruz, M., 2012. Social information and economic decision-making in the ultimatum game. Front. Neurosci. 6, 103. http://dx.doi. org/10.3389/ fnins.2012.00103.

Gehring, W.J., Fencsik, D.E., 2001. Functions of the medial frontal cortex in the processing of conflict and errors. J. Neurosci. 21 (23), 9430-9437 10.1.1.319.2578.

Gehring, W.J., Willoughby, A.R., 2002. The medial frontal cortex and the rapid processing of utility information. Science 295, 2279-2282. http://dx.doi.org/ 10.1126/science.1066893.

Giraudet, L., St-Louis, M.-E., Scannella, S., Causse, M., 2015. P300 event-related potential as an indicator of in attentional deafness? Plos One 10, e0118556. http://dx.doi.org/10.1371/journal.pone.0118556.

Glick, P., Fiske, S.T., 1996. The ambivalent sexism inventory: differentiating hostile and benevolent sexism. J. Personal. Soc. Psychol. 70, 491-512. http://dx.doi.org $10.1037 / 00223514.70 .3 .491$.

Greenwald, A.G., Banaji, M.R., Rudman, L.A., Farnham, S.D., Nosek, B.A., et al., 2000. Prologue to a unified theory of attitudes, stereotypes, and self-concept. In: Forgas, J.P. (Ed.), Feeling and Thinking: The Role of Affect in Social Cognition. Cambridge University Press, Paris, pp. 308-330.

Güth, W., Schmittberger, R., Schwarze, B., 1982. An experimental analysis of ultimatum bargaining. J. Econ. Behav. Organ. 3 (4), 367-388. http://dx.doi.org/ 10.1016/01672681(82)900117.

Güth, W., 1995. On ultimatum bargaining experiments-a personal review. J. Econ. Behav. Organ. 27, 329-344. http://dx.doi.org/10.1016/01672681(94)00071L.

Güth, W., Van Damme, E., 1998. Information, strategic behavior, and fairness in ultimatum bargaining: an experimental study. J. Math. Psychol. 42 (2), 227-247. http://dx.doi.org/10.1006/jmps.1998.1212.

Gygax, P., Gabriel, U., 2008. Can a group of musicians be composed of women? Generic interpretation of French masculine role names in the absence and presence of feminine forms. Swiss J. Psychol. 67 (3), 143-151. http://dx.doi.org/ 10.1024/14210185.67.3.143.

Holm, A., Ranta-aho, P.O., Sallinen, M., Karjalainen, P.A., Müller, K., 2006. Relationship of $\mathrm{P} 300$ single-trial responses with reaction time and preceding stimulus sequence. Int. J. Psychophysiol. 61 (2), 244-252. http://dx.doi.org 10.1016/j.ijpsycho.2005.10.015.

Holroyd, C.B., Coles, M.G.H., 2002. The neural basis of human error processing: reinforcement learning, dopamine, and the error-related negativity. Psychol. Rev. 109, 679-709. http://dx.doi.org/10.1037/0033295X.109.4.679.

Irmen, L., Roßberg, N., 2004. Gender markedness of language. The impact of grammatical and nonlinguistic information on the mental representation of person information. J. Lang. Soc. Psychol. 23 (3), 272-307. http://dx.doi.org/ $10.1177 / 0261927 \times 04266810$

Khader, P.H., Pachur, T., Meier, S., Bien, S., Jost, K., Rösler, F., 2011. Memory-based decision-making with heuristics involves increased activation of decision-relevant memory representations. J. Cogn. Neurosci. 23, 3540-3554. http://dx.doi. org/10.1162/jocn a 00059 .

Koenigs, M., Tranel, D., 2007. Irrational economic decision-making after ventromedial prefrontal damage: evidence from the ultimatum game. J. Neurosci. 27, 951-956. http://dx.doi.org/10.1523/JNEUROSCI.460606.2007.

Kok, A., 2001. On the utility of P3 amplitude as a measure of processing capacity. Psychophysiology 38, 557-577. http://dx.doi.org/10.1017/S0048577201990559.

Kubota, J.T., Jian, L., Bar-David, E., Banaji, M.R., Phelps, E.A., 2013. The price of racial bias: intergroup negotiations in the ultimatum game. Psychol. Sci. 24 (11). http: //dx.doi.org/10.1177/0956797613496435.

Lieberman, M.D., Hariri, A., Jarcho, J.M., Eisenberger, N.I., Bookheimer, S.Y., 2005. An fMRI investigation of race-related amygdala activity in African-American and Caucasian-American individuals. Nat. Neurosci. 8 (6), 720-722. http://dx.doi. org/10.1038/nn1465.

Loehr, J.D., Kourtis, D., Vesper, C., Sebanz, N., Knoblich, G., 2013. Monitoring individual and joint action outcomes in duet music performance. J. Cogn. Neurosci. 25 (7), 1049-1061. http://dx.doi.org/10.1162/jocn_a_00388. 
Luck, S.J., Kappenman, E.S., 2012. Luck, S.J., Kappenman, E.S. (Eds.), The Oxford Handbook of Event-Related Potential Components. Oxford University Press, p. 664, ISBN: 9780195374148.

MacDonald, A.W., Cohen, J.D., Stenger, V.A., Carter, C.S., 2000. Dissociating the role of the dorsolateral prefrontal cortex and anterior cingulate cortex in cognitive control. Science 288, 1835-1838. http://dx.doi.org/10.1126 science.288.5472.1835.

Manganelli, A.M., Volpato, C., Canova, L., 2008. L'atteggiamento ambiva-lente verso donne e uomini. Un contributo alla validazione delle scale ASI e AMI (Ambivalent attitudes toward women and men. A contribution to the Italian validation of ASI and AMI Scales). G. Ita. Psicol. 35, 261-287. http://dx.doi.org/ $10.1421 / 26601$.

Marchetti, A., Castelli, I., Harlé, K.M., Sanfey, A.G., 2011. Expectations and outcome: the role of proposer features in the ultimatum game. J. Econ. Psychol. 32, 446-449. http://dx.doi.org/10.1016/j.joep.2011.03.009.

Metting Van Rijn, A.C., Peper, A., Grimbergen, C.A., 1990. High-quality recording of biolectric events: Part 1 Interference reduction, theory and practice. Med. Biol. Eng. Comput. 28, 389-397. http://dx.doi.org/10.1007/BF02441961.

Miltner, W.H.R., Braun, C.H., Coles, M.G.H., 1997. Event-related brain potentials following incorrect feedback in a time-estimation task: evidence for a "generic" neural system for error detection. J. Cogn. Neurosci. 9 (6), 788-798. http://dx. doi.org/10.1162/jocn.1997.9.6.788.

Miltner, W.H.R., Lemke, U., Weiss, T., Holroyd, C., Scheffers, M.K., Coles, G.H., 2003. Implementation of error-processing in the human anterior cingulate cortex: a source analysis of the magnetic equivalent of the error-related negativity. Biol. Psychol. 64 (1-2), 157-166. http://dx.doi.org/10.1016/S03010511(03)001078.

Nieuwenhuis, S., Yeung, N., Van den Wildenberg, W., Ridderinkhof, K.R., 2003. Electrophysiological correlates of anterior cingulate function in a Go/NoGo task: effects of response conflict and trial type frequency. Cogn. Affect. Behav. Neurosci. 3, 17-26. http://dx.doi.org/10.3758/CABN.3.1.17.

Nieuwenhuis, S., Aston-Jones, G., Cohen, J.D., 2005. Decision making, the P3, and the locus coeruleus-norepinephrine system. Psychol. Bull. 131, 510-532. http: //dx.doi.org/10.1037/00332909.131.4.510.

Oakhill, J., Garnham, A., Reynolds, D., 2005. Immediate activation of stereotypical gender information. Mem. Cogn. 33 (6), 972-983. http://dx.doi.org/10.3758/ BF03193206.

Oldfield, R.C., 1971. The assessment and analysis of handedness: the Edinburgh Inventory. Neuropsychologia 9, 97-113. http://dx.doi.org/10.1016/00283932 (71)900674.

Phelan, J.C., Link, B.G., Dovidio, J.F., 2008. Stigma and prejudice: one animal or two? Soc. Sci. Med. 67, 358-367 10.1016 /j.socscimed.2008.03.022.

Pillutla, M.M., Murnighan, J.K., 1996. Unfairness, anger, and spite: emotional rejections of ultimatum offers. Organ. Behav. Hum. Decis. Processes 68, 208-224. http://dx.doi.org/10.1006/obhd.1996.0100.

Polezzi, D., Daum, I., Rubaltelli, E., Lotto, L., Civai, C., Sartori, G., Rumiati, R., 2008. Mentalizing in economic decision-making. Behav. Brain Res. 190, 218-223. http://dx.doi.org/10.1016/j.bbr.2008.03.003.

Polich, J., 2007. Updating P300: an integrative theory of P3a and P3b. Clin. Neurophysiol. 118 (10), 2128-2148. http://dx.doi.org/10.1016/j.clinph.2007.04.019.

Pyykkönen, P., Hyönä, J., Van Gompel, R.P.G., 2010. Activating gender stereotypes during online spoken language processing: evidence from visual world eye tracking. Exp. Psychol. 57 (2), 126-133. http://dx.doi.org/10.1027/16183169 a000016.

Qu, C., Wang, Y., Huang, Y., 2013. Social exclusion modulates fairness consideration in the ultimatum game: an ERP study. Front. Hum. Neurosci. 7, 505. http://dx. doi.org/10.3389/fnhum.2013.00505.

Quadflieg, S., Macrae, N.C., 2011. Stereotypes and stereotyping: What's the brain got to do with it? Eur. Rev. Soc. Psychol. 22, 215-273. http://dx.doi.org/10.1080/ 10463283.2011.627998.

Rabin, M., 1993. Incorporating fairness into game theory and economics. Am. Econ. Rev. 83, 1281-1302

Reynolds, D.J., Garnham, A., Oakhill, J., 2006. Evidence of immediate activation of gender information from a social role name. Q. J. Exp. Psychol. 59 (5), 886-903. http://dx.doi.org/10.1080/02724980543000088.

Richeson, J.A., Baird, A.A., Gordon, H.L., Heatherton, T.F., Wyland, C.L., Trawalter, S. Shelton, J.N., 2003. An fMRI investigation of the impact of interracial contact on executive function. Nat. Neurosci. 6, 1323-1328. http://dx.doi.org/10.1038/ nn1156.

Ridgeway, C.L., 2001. Gender, status, and leadership. J. Soc. Issues 57, 627-655. http://dx.doi.org/10.1111/00224537.00233.

Rilling, J.K., Sanfey, A.G., 2011. The neuroscience of social decision-making. Ann Rev. Psychol. 62, 23-48. http://dx.doi.org/10.1146/annurev. psych.121208.131647.

Roth, A.E., 1995. Bargaining Experiments. In: John, Kagel, Alvin E, Roth (Eds.), Handbook of Experimental Economics. Princeton University Press, pp. 253-348.

Rudman, L.A., 1998. Self-promotion as a risk factor for women: the costs and benefits of counterstereotypical impression management. J. Personal. Soc. Psychol. 74, 629-645. http://dx.doi.org/10.1037/00223514.74.3.629.

Rudman, L.A., Phelan, J.E., 2008. Backlash effects for disconfirming gender stereotypes in organizations. Res. Organ. Behav. 4, 61-79. http://dx.doi.org/10.1016/j. riob. 2008.04.003.

Ruz, M., Moser, A., Webster, K., 2011. Social expectations bias decision-making in uncertain inter-personal situations. PLoS One 6, e15762. http://dx.doi.org/ 10.1371/journal.pone.0015762.

Sanfey, A.G., Rilling, J.K., Aronson, J.A., Nystrom, L.E., Cohen, J.D., 2003. The neural basis of economic decision-making in the ultimatum game. Science 300 (5626) 1755-1758. http://dx.doi.org/10.1126/science.1082976.

Sanfey, A.G., Chang, L.J., 2008. Multiple systems in decision-making. Ann. N. Y. Acad. Sci. 1128, 53-62. http://dx.doi.org/10.1196/annals.1399.007.

Sanfey, A.G., 2009. Expectations and social decision-making: biasing effects of prior knowledge on ultimatum responses. Mind Soc. 8, 93-107. http://dx.doi.org/ $10.1007 / \mathrm{s} 1129900900536$.

Siyanova-Chanturia, A., Pesciarelli, F., Cacciari, C., 2012. The electrophysiological underpinnings of processing gender stereotypes in language. PloS One 7 (12) e48712. http://dx.doi.org/10.1371/journal.pone.0048712.

Solnick, S.J., Schweitzer, M., 1999. The influence of physical appearance and gende on ultimatum game decisions. Organ. Behav. Hum. Decis. Processes 79 (3) 199-215. http://dx.doi.org/10.1006/obhd.1999.2843.

Solnick, S.I., 2001. Gender differences in the ultimatum game. Econ. Inquiry 39 (2) 189-200. http://dx.doi.org/10.1111/j.1465-7295.2001.tb00060.x.

Sutter, M., 2007. Outcomes versus intentions: On the nature of fair behavior and its development with age. J. Econ. Psychol. 28 (1), 69-78. http://dx.doi.org/ 10.1016/j.joep.2006.09.001.

Thaler, R.H., 1988. Anomalies: the ultimatum game. J. Econ. Perspect. Am. Econ. Assoc. 2 (4), 195-206. http://dx.doi.org/10.1257/jep.2.4.195.

Van't Wout, M., Kahn, R.S., Sanfey, A.G., Aleman, A., 2006. Affective state and decision-making in the Ultimatum Game. Exp. Brain Res. 169, 564-568. http://dx doi.org/10.1007/s00221-006-0346-5.

Verleger, R., 1988. Event-related potentials and cognition: a critique of the contextupdating hypothesis and an alternative interpretation of P3. J. Behav. Brain Sci. 11, 343-356. http://dx.doi.org/10.1017/S0140525 × 00058015.

Walsh, M.M., Anderson, J.R., 2012. Learning from experience: event-related potential correlates of reward processing, neural adaptation, and behavioral choice. Neurosci. Biobehav. Rev. 36 (8), 1870-1884. http://dx.doi.org/10.1016/i. neubiorev.2012.05.008.

Wheeler, S.C., Petty, R.E., 2001. The effects of stereotype activation on behavior: a review of possible mechanisms. Psychol. Bull. 127 (6), 797-826, doi: 10.1037 00332909.127.6.797.

Wood, W., Eagly, A.H., 2002. A cross-cultural analysis of the behavior of women and men: implications for the origins of sex differences. Psychol. Bull. 128 (5), 699 http://dx.doi.org/10.1037/00332909.128.5.699.

Wu, Y., Zhou, Y., Van Dijk, E., Leliveld, M.C., Zhou, X., 2011. Social comparison affects brain responses to fairness in asset division: an ERP study with the ultimatum game. Front. Hum. Neurosci. 5, 131. http://dx.doi.org/10.3389/ fnhum.2011.00131.

Wu, Y., Hu, J., van Dijk, E., Leliveld, M.C., Zhou, X., 2012. Brain activity in fairness consideration during asset distribution: Does the initial ownership play a role? PLoS One 7 (6), e39627. http://dx.doi.org/10.1371/journal.pone.0039627.

Yeung, N., Botvinick, M.M., Cohen, J.D., 2004. The neural basis of error detection: conflict monitoring and the error-related negativity. Psychol. Rev. 111, 931-959. http://dx.doi.org/10.1037/0033-295X.111.4.931. 